\title{
Postoperative pain and analgesic responses are similar in male and female Sprague-Dawley rats
} [Les réactions à la douleur postopératoire et aux analgésiques sont similaires chez les rats et les rates Sprague-Dawley]

Jeffrey S. Kroin PhD, Asokumar Buvanendran MD, Subhash K.S. Nagalla MD, Kenneth J. Tuman MD

Purpose: Controversy exists concerning the influence of gender on pain sensitivity and response to analgesics both in animal and human studies. The present study compares postoperative pain scores in male and female rats and how they respond to analgesic interventions.

Methods: Unilateral plantar foot incisions were made in SpragueDawley rats of both genders, producing mechanical allodynia in an established model of postoperative pain. Postoperative pain scores were monitored for four days following incision to identify intrinsic differences between the two groups. Animals were tested with analgesics (opioids, $\alpha_{2}$-adrenergic agonists, acetylcholine esterase inhibitors, gabapentin) both systemically and intrathecally on the day after incision to assess gender differences in the anti-allodynic effect of these drugs.

Results: In the plantar foot incision model of postoperative pain there was no gender difference in postoperative mechanical hypersensitivity (von Frey filaments) over four days. Morphine $\left(3 \mathrm{mg} \cdot \mathrm{kg}^{-1}\right)$ and gabapentin $\left(25 \mathrm{mg} \cdot \mathrm{kg}^{-1}\right.$ ) administered intraperitoneally decreased postoperative mechanical hypersensitivity, but with no gender difference. Intrathecal morphine ( $1-2 \mathrm{nmol})$, gabapentin $(60-120 \mathrm{nmol})$, clonidine $(45 \mathrm{nmol})$, and neostigmine $(6.6 \mathrm{nmol})$ also showed no gender difference in analgesic effect.

Conclusion: The results of this study demonstrate that in SpragueDawley rats there are no gender differences in postoperative pain perception or the response to analgesics, indicating that this strain of rats can be used without introducing gender bias in studies of postoperative pain.

Objectif : L'influence du sexe sur la sensibilité à la douleur et la réaction aux analgésiques ne fait pas l'unanimité dans les études chez l'animal et chez l'humain. La présente étude compare les scores de douleur postopératoire et la réaction aux analgésiques entre des rats et des rates.
Méthode : Des incisions unilatérales à la plante du pied ont été faites chez des rats et des rates Sprague-Dawley, ce qui a produit une allodynie mécanique selon un modèle connu de douleur postopératoire. Les scores de douleur postopératoire ont été enregistrés pendant quatre jours après les incisions afin d'établir des différences intrinsèques entre les deux groupes. Les animaux ont été testés avec des analgésiques (opiö̈des, agonistes $\alpha_{2}$-adrénergiques, inhibiteurs de l'acétylcholine estérase, gabapentine) systémiques et intrathécaux le jour suivant l'incision pour évaluer les différences de l'effet anti-allodynique de ces médicaments selon le sexe de l'animal.

Résultats : Chez le modèle de douleur postopératoire avec incision plantaire, il n'y avait pas de différence d'hypersensibilité mécanique postopératoire (filaments von Frey) reliée au sexe. Avec l'administration intrapéritonéale de morphine (3 $\mathrm{mg} \cdot \mathrm{kg}^{-1}$ ) et de gabapentine (25 $\mathrm{mg} \cdot \mathrm{kg}^{-1}$ ), l'hypersensibilité mécanique postopératoire a été réduite, sans différence entre les sexes. L'administration intrathécale de morphine ( $1-2 \mathrm{nmol})$, de gabapentine (60-120 nmol), de clonidine (45 $\mathrm{nmol})$ et de néostigmine $(6,6 \mathrm{nmol})$ n'a pas montré non plus de différence d'effet analgésique reliée au sexe.

Conclusion : Les résultats de l'étude démontrent que chez les rats Sprague-Dawley, il n'y a pas de différence reliée au sexe quant à la perception de la douleur postopératoire ou à la réaction aux analgésiques, ce qui indique qu'on peut utiliser cette lignée de rats pour des études sur la douleur postopératoire sans devoir introduire le biais du sexe.

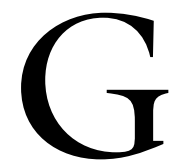

ENDER differences have been reported in some, but not all, animal pain studies. In Sprague-Dawley rats given noxious thermal stimuli (hot plate test), there was no gender difference in baseline nociceptive scores. ${ }^{1,2}$ In contrast, in another heat nociception study (tail flick test) male Sprague-Dawley rats were more sensitive to

From the Department of Anesthesiology, Rush Medical College, Chicago, Illinois, USA.

Address correspondence to: Dr. Jeffrey S. Kroin, Department of Anesthesiology, Rush Medical College, 1653 West Congress Parkway,

Chicago, IL 60612, USA. Phone: 312-942-6460; Fax: 312-942-8858; E-mail: jkroin@rush.edu

Accepted for publication March 26, 2003.

Revision accepted July 2, 2003. 
painful stimuli than females, although in the WistarKyoto strain there was no gender difference and in the Long-Evans strain it was the female rats that were more sensitive to thermal stimuli. ${ }^{3}$ The influence of gender on postoperative pain has not been studied in any animal model.

In the hot plate and tail flick tests, male rats usually have more antinociception than female rats after the same systemic dose of morphine. ${ }^{1-4}$ However, in one of these studies, the gender-sensitive antinociceptive response to morphine varied depending on the strain of the rat. ${ }^{3}$ Morphine sensitivity as a function of gender has not been examined in postoperative pain models. Animal studies have examined the influence of the estrus cycle on pain sensitivity ${ }^{5,6}$ and brain $\mu$-opiate receptor concentrations. ${ }^{7}$ In normally cycling rats, inflammatory hyperalgesia did not differ between proestrus and diestrus phases. ${ }^{8}$

With so many dependent variables (species, strain, pain model, nociceptive stimulus, phase of estrus cycle, analgesic administered) it is difficult to formulate a definite conclusion based on the literature about the role of gender in pain sensitivity and response to analgesics. In this study, we selected one commonly used strain of rats (to avoid strain variability) and randomly tested animals throughout the week (to minimize differences due to estrus cycle) using a postoperative pain model to assess gender differences in baseline mechanical allodynia and sensitivity to commonly used analgesics, administered systemically and intrathecally.

\section{Methods \\ Animals}

Experiments on 238 rats were approved by the Institutional Animal Care and Use Committee. Young Sprague-Dawley rats (Sasco SD, Charles River Labs, Madison, WI, USA) of either gender were agematched to be $73-75$ days old at the time of initial surgery. Male rats weighed on average $290 \mathrm{~g}$ and female rats $215 \mathrm{~g}$. Female rats were tested randomly throughout the estrus cycle. ${ }^{3}$ All testing was performed between 08:00 and 12:00 hr. Following surgery, animals were single-caged for the remainder of the study.

\section{Postoperative pain model}

Under isoflurane anesthesia, an intrathecal catheter (polyethylene, $0.6 \mathrm{~mm}$ outer diameter) for bolus drug injection was implanted into the spinal subarachnoid space via the cisterna magna. ${ }^{9}, 10$ The catheter tip was adjacent to the lumbar enlargement, and the catheter internal volume was $7 \mu \mathrm{L}$. After a seven-day recovery period and exclusion of animals with postsurgical neurological deficits ( $8 \%$ of the animals implanted), postoperative pain was induced with a left plantar foot incision following the model of Brennan et al. ${ }^{11}$ Briefly, a \#11 scalpel blade was used to create a 10$\mathrm{mm}$ long incision through the skin and into the underlying muscle. ${ }^{10,11}$ The wound was closed with 40 nylon sutures using a horizontal mattress pattern.

The following morning, animals were placed on a metal grid and allowed to accommodate to the surroundings for $20 \mathrm{~min}$. Mechanical hyperalgesia was measured with calibrated von Frey filaments (12-288 $\mathrm{mN}$ ) applied medial to the incision. There was a 20sec period between successive filaments. The lowest withdrawal force in three trials (five minutes separating each trial) was used in the analysis, ${ }^{11}$ with animals not responding to the $288 \mathrm{mN}$ filament assigned a $300 \mathrm{mN}$ cutoff value (equivalent to $30.6 \mathrm{~g}$ ). Mechanical hyperalgesia was also examined on the next three mornings. Withdrawal force was compared between genders $(n=20 /$ gender $)$ with the MannWhitney $\mathrm{U}$ test, applying Bonferroni correction for multiple day $(n=4)$ comparisons.

\section{Pharmacological study}

On the day after skin incision, baseline von Frey filament testing was performed, and animals received ip $(0.5 \mathrm{~mL})$ morphine sulfate, $\mathrm{l}$ and $3 \mathrm{mg} \cdot \mathrm{kg}^{-1}$ or gabapentin $25 \mathrm{mg} \cdot \mathrm{kg}^{-1}$; or intrathecal $(8 \mu \mathrm{L})$ morphine sulfate, 1 and $2 \mathrm{nmol}(0.38$ and $0.76 \mu \mathrm{g})$, gabapentin, 60 and $120 \mathrm{nmol}$ ( 10 and $20 \mu \mathrm{g}$ ), clonidine hydrochloride, $45 \mathrm{nmol}(12 \mu \mathrm{g})$, or neostigmine methylsulfate, $6.6 \mathrm{nmol}(2 \mu \mathrm{g})$. Intrathecal doses were not adjusted for body weight, based on previous data from a population of rats of both gender indicating that cerebrospinal fluid volume does not vary significantly even when body weight varies more than twofold in rats. ${ }^{12}$ At every dose, ten animals of each gender were tested. After injection, the animal was returned to the grid, and mechanical hyperalgesia was then re-evaluated $30 \mathrm{~min}$ later (or $60 \mathrm{~min}$ for gabapentin). Sedation was also evaluated (immediately after the 30 or 60 min hyperalgesia testing) based on the animal's ability to stay on a rotating rod $(10 \mathrm{rpm})$ for $180 \mathrm{sec}$. It was impossible to blind the observers to the gender of the animal that they were testing, however, the observers were not informed that this was a project to study gender differences. Observers were blinded to the drug and dose assignments and were only informed that this was a general study examining the relative effectiveness of common analgesic drugs in a postoperative pain model. Withdrawal force was compared pre- and postinjection with the Wilcoxon signed rank test and between gen- 


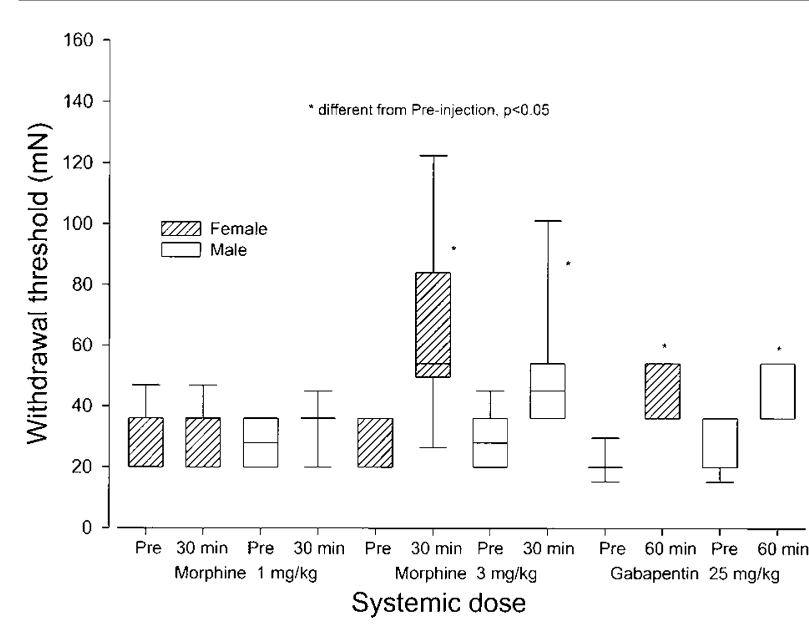

FIGURE 1 Withdrawal threshold in $\mathrm{mN}$ to calibrated von Frey filaments applied to the left medial plantar hindpaw following surgical incision the previous day. Testing was performed on female and male rats prior to $i p$ drug injection (pre) and at $30 \mathrm{~min}$ after injection for morphine or at $60 \mathrm{~min}$ after injection for gabapentin. There were ten animals per injection for each gender. The results are expressed as medians (horizontal line) with first and third quartiles (boxes), and ten and 90 percentiles (error bars). Where no actual box is displayed $8 / 10$ animals had the same threshold, and so only the median line appears.

ders with the Mann-Whitney $U$ test, applying Bonferroni correction for multiple comparisons of the same drug and route of administration.

\section{Results}

Following unilateral plantar foot incision, there were no differences in the postoperative pain scores between male and female rats at one, two, three, or four days after surgery. Animals were tested in an identical manner on all four days. Median withdrawal threshold was between $20-36 \mathrm{mN}(300 \mathrm{mN}$ prior to foot incision) on each of the days.

With systemic (ip) drug injection, withdrawal threshold increased in both male and female rats administered $3 \mathrm{mg} \cdot \mathrm{kg}^{-1}$, but not $1 \mathrm{mg} \cdot \mathrm{kg}^{-1}$, morphine (Figure 1). Mechanical thresholds also increased in male and female rats administered systemic gabapentin at the $25 \mathrm{mg} \cdot \mathrm{kg}^{-1}$ dose. With all drugs administered systemically, there was no gender difference in the postinjection withdrawal threshold.

Intrathecal morphine, $1 \mathrm{nmol}$, increased median withdrawal threshold similarly in both male and female rats (Figure 2). Since preinjection scores did not differ based on gender (Figure 1), only the postin-

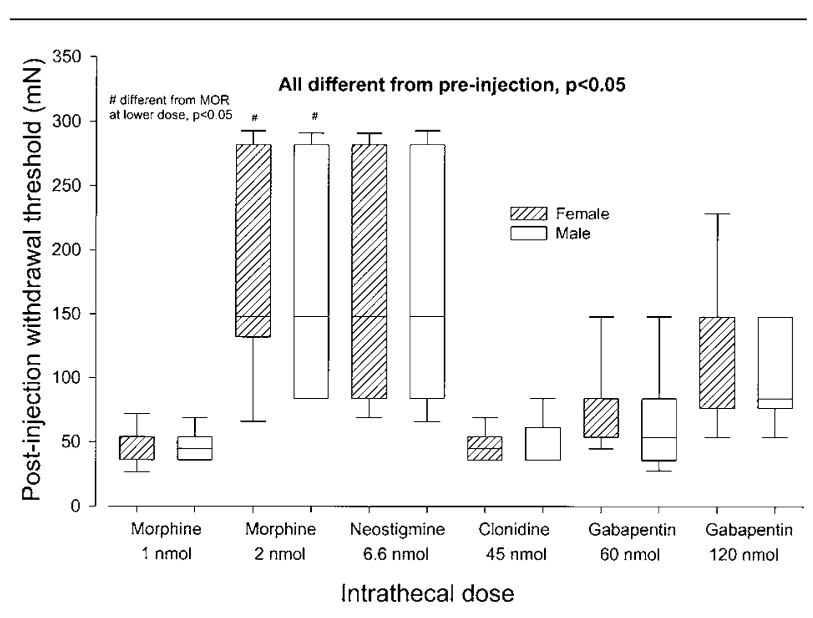

FIGURE 2 Withdrawal threshold in $\mathrm{mN}$ to calibrated von Frey filaments applied to the left medial plantar hindpaw following surgical incision the previous day. Testing was performed on female and male rats at $30 \mathrm{~min}$ after intrathecal injection for morphine, neostigmine, and clonidine, or at $60 \mathrm{~min}$ after injection for gabapentin. There were ten animals per injection for each gender. At the doses presented in this figure, all of the withdrawal thresholds were greater than prior to injection (typical pre-injection values shown in Figure 1).

jection values are displayed. At the 2 nmol dose, thresholds were increased more than at $1 \mathrm{nmol}$. Withdrawal force increased similarly in both male and female rats following intrathecal neostigmine, 6.6 nmol. Intrathecal clonidine, $45 \mathrm{nmol}$, and gabapentin, 60 or $120 \mathrm{nmol}$, also increased withdrawal threshold similarly in both male and female rats. With all drugs tested intrathecally, there was no difference in withdrawal threshold between the genders. No sedation was seen at any of the doses (systemic or intrathecal) used in this study.

\section{Discussion}

The results of this study, in one strain of rats, do not support a hypothesis that females have lower postoperative pain thresholds than males, or that males obtain more analgesia from opioids. Daily postoperative pain scores (mechanical hyperalgesia) did not differ based on gender. It should be cautioned that our study included only one postoperative pain model and one sensory modality of pain. Following either systemic or intrathecal drug administration, the antihyperalgesic effect in the postoperative pain model did not differ between male and female Sprague-Dawley 
rats. This was true with morphine, as well as other analgesic drugs commonly used in research studies: gabapentin, clonidine, and neostigmine. A full doseresponse study to identify an exact $\mathrm{ED}_{50}$ for each drug and gender was not justified because of the absence of any indication that this would change the overall negative findings for any drug or route of administration.

In a recent study, women undergoing arthroscopic anterior cruciate ligament reconstruction reported higher pain scores than men, at rest as well as with activity, on the first postoperative day. ${ }^{13}$ However, the authors suggest the possibility that the gender difference may be related to differences in use of concurrent medications (acetaminophen, bupivacaine, nonsteroidal anti-inflammatory drugs, and oxycodone). Burns et al. ${ }^{14}$ found that following upper abdominal surgery, men required more morphine than women to achieve similar pain relief. While no clear explanation was given, the role of personality as a postoperative factor was considered. ${ }^{15}$ In our rat study, there was no difference in pain scores, and without the potential influence of psychosocial factors, no difference in morphine sensitivity. Following extraction of impacted wisdom teeth, the kappa opioid agonist nalbuphine produced a greater analgesic response in women than men. ${ }^{16}$ However, in that study the findings are confounded by the observation that at some doses this drug worsened pain perception in men, while women experienced analgesia only at the $10 \mathrm{mg}$ dose, but not the 5 or $20 \mathrm{mg}$ dose.

One interesting possibility is that gender differences in drug metabolism could result in a sex difference in analgesic effect. In a recent study in Sprague-Dawley rats, males displayed twofold higher antinociception (hot plate test) to a very high dose $\left(20 \mathrm{mg} \cdot \mathrm{kg}^{-1}\right)$ of systemic morphine than females. ${ }^{2}$ These female rats had a threefold higher plasma level of morphine-3-glucuronide, a reputed functional antagonist to morphine, which the authors suggest could account for morphine being less effective in females. ${ }^{2}$ In our study, we tested morphine intrathecally, as well as systemically (up to $3 \mathrm{mg} \cdot \mathrm{kg}^{-1}$ ), in a different pain model and found no gender difference. With intrathecal administration, differences in drug metabolism due to gender are unlikely to be a contributing factor in analgesic response.

The findings of the present study do not preclude the existence of fundamental gender-related differences in postoperative pain or analgesia that may exist throughout the mammalian order. Nonetheless, using a clinically relevant postoperative pain model we did not observe gender differences in the rat strain we evaluated. Only commonly used potent analgesics were examined and there may be other compounds that differentially effect antiallodynic responses based on gender. We only examined mechanical allodynia in our study since that most closely relates to symptoms (e.g., movement related pain) seen in patients postoperatively, however it is possible that there may be differences in other sensory modalities (e.g., thermal hypersensitivity) that were not evaluated in our rat study. Choice of rat strain may be an important factor in determining gender differences in pain, ${ }^{3,17}$ and there may be other strains of rats that may evidence gender differences in postoperative pain. The results of this study demonstrate that in Sprague-Dawley rats there are no gender differences in postoperative pain perception or the response to analgesics, indicating that this strain of rats can be used without introducing gender bias in studies of postoperative pain.

\section{References}

1 Cicero TJ, Nock B, Meyer ER. Sex-related differences in morphine's antinociceptive activity: relationship to serum and brain morphine concentrations. J Pharmacol Exp Ther 1997; 282: 939-44.

2 Baker L, Ratka A. Sex-specific differences in levels of morphine, morphine-3-glucuronide, and morphine antinociception in rats. Pain 2002; 95: 65-74.

3 Mogil JS, Chesler EJ, Wilson SG, Juraska JM, Sternberg $W F$. Sex differences in thermal nociception and morphine antinociception in rodents depend on genotype. Neurosci Biobehav Rev 2000; 24: 375-89.

4 Cook CD, Barrett AC, Roach EL, Bowman JR, Picker $M J$. Sex-related differences in the antinociceptive effects of opioids: importance of rat genotype, nociceptive stimulus intensity, and efficacy at the $\mu$ opioid receptor. Psychopharmacology (Berl) 2000; 150: $430-42$.

5 Kepler KL, Kest B, Kiefel JM, Cooper ML, Bodnar RJ. Roles of gender, gonadectomy and estrous phase in the analgesic effects of intracerebroventricular morphine in rats. Pharmacol Biochem Behav 1989; 34: 119-27.

6 Frye $C A$, Bock BC, Kanarek RB. Hormonal milieu effects tailflick latency in female rats and may be attenuated by access to sucrose. Physiol Behav 1992; 52: 699-706.

7 Limonta P, Maggi R, Dondi D, Martini L, Piva F. Gonadal steroid modulation of brain opioid systems. J Steroid Biochem 1987; 27: 691-8.

8 Ren K, Wei F, Dubner R, Murphy A, Hoffman GE. Progesterone attenuates persistent inflammatory hyperalgesia in female rats: involvement of spinal NMDA receptor mechanisms. Brain Res 2000; 865: 272-7.

9 Stevens CW, Yaksh TL. Dynorphin A and related peptides administered intrathecally in the rat: a search for 
putative kappa opiate receptor activity. J Pharmacol

Exp Ther 1986; 238: 833-8.

10 Kroin JS, McCarthy RJ, Von Roenn N, Schwab B,

Tuman KJ, Ivankovich AD. Magnesium sulfate potentiates morphine antinociception at the spinal level. Anesth Analg 2000; 90: 913-7.

11 Brennan TJ, Vandermeulen EP, Gebhart GF.

Characterization of a rat model of incisional pain. Pain 1996; 64: 493-501.

12 Bass NH, Lundborg P. Postnatal development of bulk flow in the cerebrospinal fluid system of the albino rat: clearance of carboxyl- $\left[{ }^{14} \mathrm{C}\right]$ inulin after intrathecal infusion. Brain Res 1973; 52: 323-32.

13 Taenzer AH, Clark C, Curry CS. Gender effects report of pain and function after arthroscopic anterior cruciate ligament reconstruction. Anesthesiology 2000; 93: 670-5.

14 Burns JW, Hodsman NBA, McLintock TTC, Gillies GWA, Kenny GNC, McArdle CS. The influence of patient characteristics on the requirements for postoperative analgesia. A reassessment using patient-controlled analgesia. Anaesthesia 1989; 44: 2-6.

15 Boyle P, Parbrook GD. The interrelation of personality and postoperative factors. Br J Anaesth 1977; 49: 259-64.

16 Gear RW, Miaskowsky C, Gordon NC, Paul SM, Heller $P H$, Levine JD. The kappa opioid nalbuphine produces gender- and dose-dependent analgesia and antianalgesia in patients with postoperative pain. Pain 1999; 83: 339-45.

17 DeLeo JA, Rutkowski MD. Gender differences in rat neuropathic pain sensitivity is dependent on strain. Neurosci Lett 2000; 282: 197-9. 